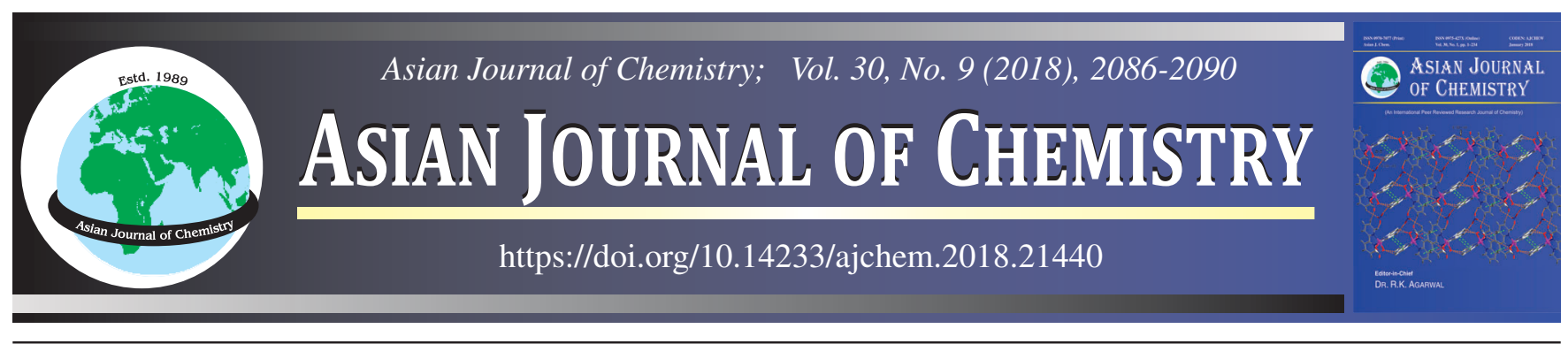

\title{
Isoflavonoids and Phytoestrogens from Pueraria candollei var. mirifica Related with Appropriate Ratios of Ethanol Extraction
}

\section{N. Peerakam ${ }^{1,2}$, P. Sirisa-Ard ${ }^{1, *}$, N. Quoc Huy ${ }^{3}$, T. Van On ${ }^{3}$, P. Tuan Long ${ }^{4}$ and A. Intharuksa ${ }^{1}$}

${ }^{1}$ Faculty of Pharmacy, Chiang Mai University, Chiang Mai 50200, Thailand

${ }^{2}$ Faculty of Pharmaceutical Sciences, Burapha University, Chonburi 20130, Thailand

${ }^{3}$ Hanoi University of Pharmacy, Hanoi City, Vietnam

${ }^{4}$ Ministry of Science and Technology (MOST), Hanoi, Vietnam

*Corresponding author: Fax: +66 53 944390; Tel: +66 53 944342; E-mail: pmpti008@ gmail.com; nichakanp3@ gmail.com

Received: 12 May 2018;

Accepted: 18 June 2018;

Published online: 31 July 2018;

AJC-19025

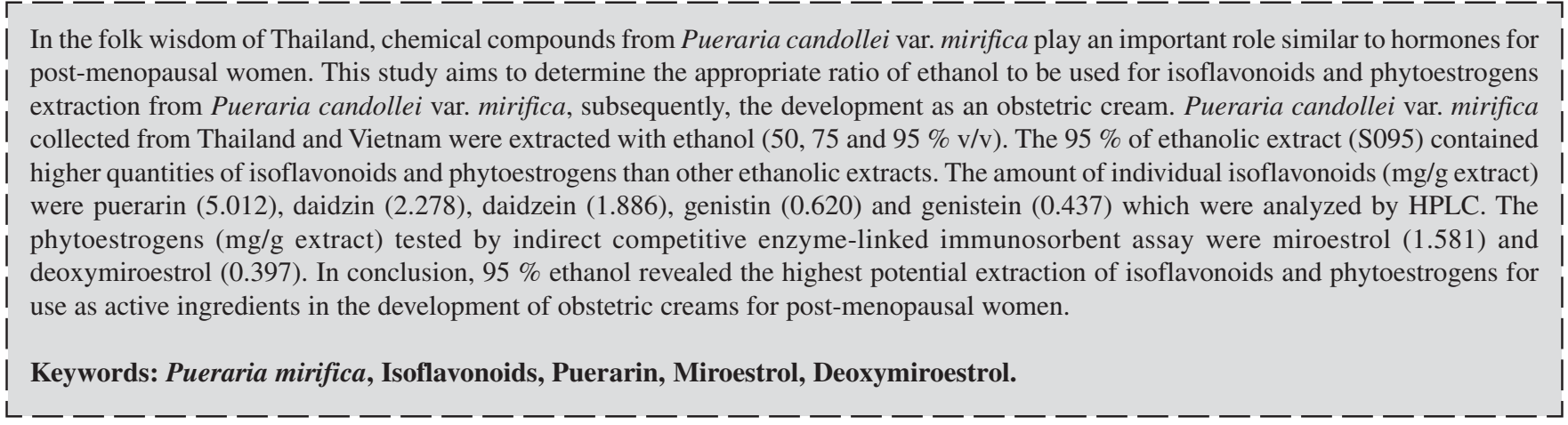

\section{INTRODUCTION}

Pueraria candollei var. mirifica (Air Shaw \& Suvat.) Niyomdham is a member of the family Leguminosae and is well known in Thailand as Kwao Krua Khaw or white Kwao Krua. This plant is usually found in the northern part of Thailand [1]. Pueraria candollei var. mirifica has been mentioned as a rejuvenation elixir and a source of good health by Luang Anusan Sunthorn in 1931 [2]. Since ancient times this plant has been used by native Thai people as folk medicine for women to treat menopausal syndrome and to increase sexual desire [3]. Previous studies have reported this medicinal herb provided benefits such as rejuvenating properties [1], to prevent osteoporosis in elderly hypogonadism subjects [4] and also showed estrogenic activity [3]. The tuberous roots of the plant contain active chemical constituents of phytoestrogen compounds such as miroestrol, deoxymiroestrol and isomiroestrol as well as isoflavonoids [5-7]. Miroestrol has similar structure as endogenous estrogen that is found in the human body and having estrogenic-link properties [5,8,9] and also showed function of estrogenic properties in ovariectomized rats [10]. Miroestrol and deoxymiroestrol were reported to enhance the effects of toremifene on MCF-7 human breast cancer cells [6]. The pharmacological activity indicated that miroestrol and deoxymiroestrol are potentially similar to estradiol [11,12]. It was suggested that miroestrol was produced from the oxidation of deoxymiroestrol [6]. Both compounds are highly active phytoestrogens [13]. Miroestrol was estimated to have activity $0.25 \times 10^{-1}$ times similar to $17 \beta$-estradiol in the rat virginal cornification assay [14]. Furthermore the isoflavonoids characterized in Pueraria candollei var. mirifica such as puerarin, daidzin and genistin are isoflavone glycosides and also daidzein and genistein are isoflavones $[1,7,15,16]$ as shown in Fig. 1. They are used as a standardization for active compounds in Pueraria candollei var. mirifica [16] and also showed in vitro activities of antioxidant, antimutagenic, anticarcino-

This is an open access journal, and articles are distributed under the terms of the Creative Commons Attribution-NonCommercial 4.0 International (CC BY-NC 4.0) License, which allows others to copy and redistribute the material in any medium or format, remix, transform, and build upon the material, as long as appropriate credit is given and the new creations are licensed under the identical terms. 

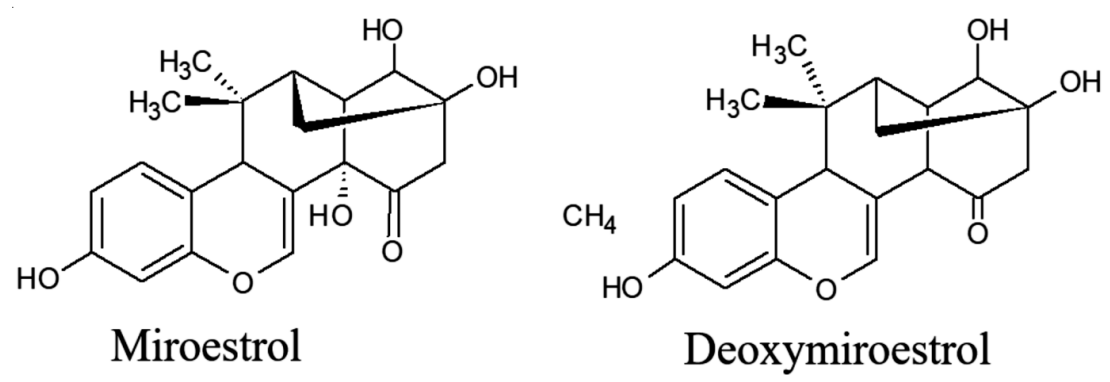<smiles>O=c1c(-c2ccc(O)cc2)coc2c(Cl)c(O)ccc12</smiles><smiles>O=c1c(-c2ccc(O)cc2)coc2cc(O[C@@H]3C[C@H](O)[C@H](O)[C@H](CO)O3)ccc12</smiles>

Daidzin<smiles>O=c1c(-c2ccc(O)cc2)coc2cc(OC3C(O)C(O)C(O)C(O)C3O)cc(O)c12</smiles>

Genistin<smiles>O=c1c(-c2ccc(O)cc2)coc2cc(O)ccc12</smiles>

Daidzein<smiles>O=c1c(-c2ccc(O)cc2)coc2cc(O)cc(O)c12</smiles>

Genistein

Fig. 1. Structure of active compounds from Pueraria candollei var. mirifica

genic and antiproliferative [17-19]. However, certain factors have affected the content of the active compounds in plants such as cultivation area, water, temperature, atmosphere, sample age as well as the period of harvesting [20]. In addition, the extraction solvent used to obtain active phytochemicals is also very important. Many studies used different solvents for extraction such as hexane, ethyl acetate, methanol and ethanol $[6,21,22]$. Although previously research compared the ratio of ethanol and methanol in water from $30-80 \%$ found that the optimum yield of isoflavone were extracted using a $70 \%$ ethanol mixture [23] and some other research presented that methanol: water (90:10) was the best solvent mixture to extract isoflavones from soybeans [24]. In our opinion the solvent used including the method for extraction should be easy and safe for workers and for development of products in the future. Therefore, the aim of this study focuses on only the used of ethanol which is safe for crude Pueraria candollei var. mirifica extract for our further development as obstetric products for post-menopausal women. We wish to discover appropriate ratios of ethanol solvent to extract the active compounds of isoflavonoids and phytoestrogens (miroestrol and deoxymiroestrol) from Pueraria candollei var. mirifica that is cultivated in Thailand and Vietnam for selection of Pueraria candollei var. mirifica extract for product development.

\section{EXPERIMENTAL}

Tuberous roots of Pueraria candollei var. mirifica were collected from the Central Laboratory and Greenhouse Complex,
Kasetsart University, Kampang Saen Campus, Nakhon Pathom, Thailand. The sample from Vietnam was selected from the jungle at Bac Giang Province (Northern Province of Vietnam), Vietnam. Voucher specimens (No. CMU023231 and CMU023232) were identified and kept at Herbarium of Faculty of Pharmacy, Chiang Mai University and HNIP herbarium of Hanoi University of Pharmacy, Vietnam.

All of the chemical standard analytical grade namely puerarin, daidzin, genistin, daidzein and genistein including ovalbumin (OVA) and bovine serum albumin (BSA) were purchased from Sigma-Aldrich, USA. Miroestrol and deoxymiroestrol as authentic standard were purified from the tuberous root of Pueraria candollei var. mirifica and was confirmed by NMR spectra. The organic solvent HPLC grade for chromatography was purchased from Fisher Scientific, Belgium. The solvent for extraction was purchased from Government Pharmaceutical Organization, Thailand and the other chemical reagents were purchased as an analytical grade. HPLC system control and data processing were carried out by Waters e2695 Separation Module and Alliance Waters 2998 PDA. The reversed phase column used Xselect ${ }^{\circledR}$ HSS C18 $(2.5 \mu \mathrm{m}, 3.0 \times 75 \mathrm{~mm})$ $\mathrm{XP}$ col waters. The membrane filter used for sample and mobile phase were Millipore membrane with pore size at $0.22 \mu \mathrm{m}$ with $13 \mathrm{~mm}$ and $47 \mathrm{~mm}$ diameters. The chromatogram HPLC analysis software was operated on a personal computer. The 96-well ELISA plate used Maxisorb Nunc, Roskilde, Denmark. A microplate reader used to determine the quantity of phytoestrogens and their isoflavonoids were Microplate Reader BioRad Laboratories, CA, USA. 
TABLE-1

VALIDATION DATA FROM CALIBRATION CURVES OF FIVE ISOFLAVONOIDS STANDARDS

\begin{tabular}{lccccc}
\hline \multicolumn{1}{c}{ Standards } & LOD & LOQ & Linearity range $\left(\mathrm{R}^{2}\right)$ & Accuracy $(\%$ recovery) & Precision $(\% \mathrm{RSD})$ \\
\hline Puerarin & 0.3264 & 0.9892 & 1.0000 & $84.18-111.83$ & $0.1697-0.7373$ \\
Daidzin & 0.1988 & 0.6023 & 0.9998 & $93.34-109.88$ & $1.3328-1.7575$ \\
Daidzein & 0.3991 & 1.2019 & 0.9997 & $84.34-105.71$ & $0.2528-1.7238$ \\
Genistin & 0.3485 & 1.0561 & 0.9997 & $96.55-115.58$ & $1.5782-1.9573$ \\
Genistein & 1.0561 & 0.3061 & 1.0000 & $91.76-119.46$ & $0.1740-0.6886$ \\
\hline
\end{tabular}

Acceptance criterions: Linearity range $\left(\mathrm{R}^{2}\right) \geq 0.995, \%$ Recovery $80-120$ and precision $<2$

Sample extraction: Pueraria candollei var. mirifica tubers after cleaning were sliced by an automatic machine to small pieces and oven at the temperature at $60^{\circ} \mathrm{C}$. The dried sample was ground by using a hammer mill. The sample powders were macerated with different ratios of ethanol at 50,75 and $95 \%$ for 7 days and stirred every day during the period of extraction. Then sample extract solutions were filtered and evaporated to dryness under reduced pressure. The crude extracts were kept at $4{ }^{\circ} \mathrm{C}$ until used.

Sample and standards preparation for isoflavonoids analysis: All sample extracts $(0.1000 \mathrm{~g})$ were dissolved in methanol and mixed by using the ultrasonic bath for $30 \mathrm{~min}$ then the volume was adjusted to $25 \mathrm{~mL}$. The samples were filtered with nylon membrane filter $(0.22 \mu \mathrm{m}, 13 \mathrm{~mm}$.) and transferred to vials before analysis. Standards were dissolved in methanol at the concentration range as follows: puerarin was 10-200 ppm, daidzin and genistein were 5-150 ppm, genistin and daidzein were 5-100 ppm, respectively.

Sample and standards preparation for miroestrol and deoxymiroestrol analysis: Standards and all sample extracts were dissolved in $20 \%$ ethanol before use. The extracts were subjected to at the concentration of 100-2200 $\mu \mathrm{g} / \mathrm{mL}$. Miroestrol and deoxymiroestrol concentrations were prepared in the range of $0.0625-4 \mu \mathrm{g} / \mathrm{mL}$.

Antibody preparation: Anti-deoxymiroestrol and antimiroestrol polyclonal antibody concentrations $(6.25 \mu \mathrm{g} / \mathrm{mL})$ were dissolved with $0.25 \%$ gelatin and $0.25 \%$ BSA in $0.5 \%$ Tween-20 in $10 \mathrm{mM}$ phosphate buffer solution (TPBS).

HPLC method validation: The methods were validated in terms of accuracy, precision, LOD and LOQ as well as the linearity and range of standards determined. The procedures were done followed by ICH Topic Q2B Validation of Analysis Procedures [25].

Isoflavonoids analysis: High-performance liquid chromatography (HPLC) method with some modification was used to analyze three isoflavone glycosides and two isoflavones in all crude extracts and compared with 5 isoflavonoids standards (puerarin, daidzein, daidzin, genistein and genistin) [26]. The Waters e2695 Separation Module with photodiode array detector (Waters 2998 PDA) was used. The column XSelect ${ }^{\circledR}$ HSS C18 Waters $(2.5 \mathrm{~mm}, 3.0 \mathrm{~mm} \times 75 \mathrm{~mm})$ was used for separation. The mobile phases were $0.1 \%$ formic acid in acetonitrile as line $\mathrm{A}$ and $0.1 \%$ formic acid in water as line $\mathrm{B}$. The $\%$ A was changed as follows: 0 min (10\%); $2.5 \mathrm{~min}(30 \%) ; 7$ $\min (30 \%) ; 8 \mathrm{~min}(10 \%)$ and $10 \mathrm{~min}(10 \%)$. The flow rate was $0.6 \mathrm{~mL} / \mathrm{min}$ with the column temperature of $30{ }^{\circ} \mathrm{C}$ and analysis at the wavelength of $254 \mathrm{~nm}$. The injection sample was $5 \mu \mathrm{L}$. Determinations were conducted in triplicate and the results were expressed as the mean \pm standard deviation (SD).
Deoxymiroestrol analysis: Quantitative analysis of deoxymiroestrol from all crude extracts was performed by indirect competitive enzyme-linked immunosorbent assay (icELISA) method using anti-deoxymiroestrol polyclonal antibody [27]. The 96-well ELISA plates were coated with $100 \mu \mathrm{L}$ of $5 \mu \mathrm{g} / \mathrm{mL}$ deoxymiroestrol-OVA conjugate solution prepared in $50 \mathrm{mM}$ carbonate buffer ( $\mathrm{pH} 9.6)$ and allowed to stand for $1 \mathrm{~h}$ at $37^{\circ} \mathrm{C}$. The plate was washed three times with TPBS. Then it was treated with $300 \mu \mathrm{L}$ of phosphate buffered saline containing $1 \%$ gelatin (PBSG) for $1 \mathrm{~h}$ at $37^{\circ} \mathrm{C}$ and then washed with TPBS. Standard or sample $(50 \mu \mathrm{L})$ and antideoxymiroestrol polyclonal antibody $(50 \mu \mathrm{L})$ was added and incubated for $1 \mathrm{~h}$ at $37^{\circ} \mathrm{C}$ after that washed with TPBS again. The peroxidase-conjugated goat anti-rabbit IgG diluted 1:1000 in TPBS was added to react with the antibodies binding specifically to deoxymiroestrol-OVA $(100 \mu \mathrm{L})$, incubated for $1 \mathrm{~h}$ at $37^{\circ} \mathrm{C}$ and washed with TPBS. The substrate solution consisting of $0.003 \% \mathrm{H}_{2} \mathrm{O}_{2}$ and $0.3 \mathrm{mg} / \mathrm{mL}$ of ABTS (2,2'-azino-bis(3ethylbenzthiazoline-6-sulphonic acid) in $100 \mathrm{mM}$ citrate buffer ( $\mathrm{pH}$ 4.0) was added to each well and incubated for $15 \mathrm{~min}$. The absorbance at $405 \mathrm{~nm}$ was measured using a microplate reader (Model 550 Microplate Reader BioRad Laboratories, CA, USA).

Miroestrol analysis: Indirect competitive enzyme-linked immunosorbent assay method using anti-miroestrol polyclonal antibody was used to determine miroestrol quantitation [28]. The 96-well ELISA plates were coated with $100 \mu \mathrm{L}$ of $5 \mu \mathrm{g} / \mathrm{mL}$ miroestrol-cOVA conjugate solution prepared in $50 \mathrm{mM}$ carbonate buffer ( $\mathrm{pH} 9.6)$ and incubated for $1 \mathrm{~h}$ at $37^{\circ} \mathrm{C}$ then it was washed three times with TPBS. Then the 96-well ELISA plates were treated with $300 \mu \mathrm{L}$ of PBSG for $1 \mathrm{~h}$ at $37{ }^{\circ} \mathrm{C}$ and then washed with TPBS. Then $50 \mu \mathrm{L}$ of standard or sample as well as anti-miroestrol polyclonal antibody were added and incubated for $1 \mathrm{~h}$ at $37^{\circ} \mathrm{C}$ then washed with TPBS. After that $100 \mu \mathrm{L}$ of the peroxidase-conjugated goat anti-rabbit IgG (diluted 1:1000 in TPBS) was added and incubated for $1 \mathrm{~h}$ at $37^{\circ} \mathrm{C}$ then washed with TPBS. The substrate solution $\left(0.003 \% \mathrm{H}_{2} \mathrm{O}_{2}\right.$ and $0.3 \mathrm{mg} /$ $\mathrm{mL}$ of ABTS in $100 \mathrm{mM}$ citrate buffer $\mathrm{pH}$ 4.0) was added to each well and incubated for $15 \mathrm{~min}$. The tested sample in 96well ELISA was measured at the absorbance of $405 \mathrm{~nm}$ by a microplate reader.

\section{RESULTS AND DISCUSSION}

Method validation: Validation of the methods (performed in term of linearity range, accuracy, precision, LOD and LOQ) presented that all standards showed good linearity and range of experiment were $\mathrm{R}^{2}$ between $0.9997-1.0000$ which corresponded with the correlation coefficient $\left(R^{2}\right) \geq 0.995$. The accuracy of the analysis presented in the range of 84-120\% recovery 
was still in the range of the criterion. The precision value (in term of \% RSD) was less than 2.0 which showed reproducibility of the developed method including LOD and LOQ were accepted and shown in Table- 1 .

Isoflavonoids content: The isoflavonoids contents in Pueraria candollei var. mirifica were analyzed by HPLC and compared with five isoflavonoids standards. The sample collected from Thailand and extracted with $95 \%$ ethanol (S095) clearly presented the highest amount of all isoflavonoids which were puerarin $(5.012 \mathrm{mg} / \mathrm{g}$ extract $)$, daidzin $(2.278 \mathrm{mg} / \mathrm{g}$ extract), daidzein $(1.886 \mathrm{mg} / \mathrm{g}$ extract), genistin $(0.60 \mathrm{mg} / \mathrm{g}$ extract) and genistein $(0.437 \mathrm{mg} / \mathrm{g}$ extract $)$, respectively, meanwhile the Pueraria candollei var. mirifica extract from Vietnam V075 presented their isoflavonoids approximate to V095. Puerarin was the major component followed by daidzin, daidzein, genistin and genistein, respectively (Table-2, Fig. 2). The difference amounts of the isoflavonoids were probably affected by various factors because the sample from Thailand had been grown under controlled conditions such as plant spacing, soil fertility, light and water etc. Some documents reported that the factors affecting the number of chemical constituents in plants were the species identification, location, atmospheric conditions during growth, the age of plant harvested, harvesting period, drying method, storage condition and production processes [20]. The results of our research may be related to the different factors like that of Alexander in 2001 [29] summarized as follows in Table-3. Moreover, sample selection, appropriate methods for extraction as well as solvents used are very important for initial consideration because it affects the content of active compounds from the samples as well.

Miroestrol and deoxymiroestrol contents: For miroestrol and deoxymiroestrol quantities which were determined by icELISA using anti-miroestrol and anti-deoxymiroestrol polyclonal antibodies. The results demonstrated that miroestrol

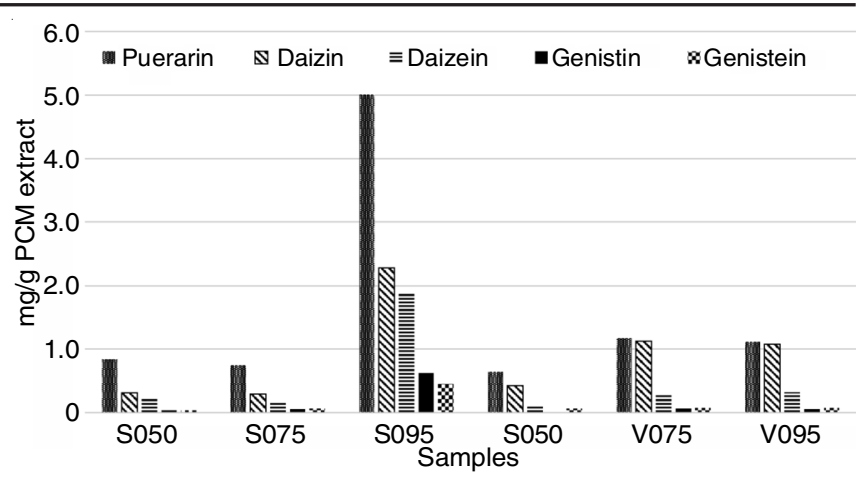

Fig. 2. Quantity of isoflavonoids from Pueraria candollei var. mirifica from Thailand and Vietnam with different solvents ratios of extraction

content is higher than deoxymiroestrol for all types of Pueraria candollei var. mirifica extracts since deoxymiroestrol can be degraded to miroestrol over the storage time and extraction process $[6,11]$. The sample from Thailand presented a higher quantity of miroestrol and deoxymiroestrol than the sample from Vietnam in all different ratios of solvent extraction. When comparing the effect of solvent for extraction, the content of miroestrol and deoxymiroestrol can be ordered as S095, S075 and S050, respectively. The same trend was observed in samples from Vietnam as shown in Table-4 and Fig. 3. Therefore, the appropriate solvent for extraction miroestrol and deoxymyroestrol from Pueraria candollei var. mirifica extract is $95 \%$ ethanol.

\section{Conclusion}

This study concluded that the ratios used for solvent extraction effected the quantity of active compounds in Pueraria candollei var. mirifica. The isoflavonoids and phytoestrogens showed highest amounts when $95 \%$ ethanol was used. This solvent is clearly shown to be the appropriate solvent for extraction. These results can be used for standardization of

TABLE-2

QUANTITY OF FIVE ISOFLAVOINOIDS FOUND IN Pueraria candollei var. mirifica EXTRACTS

\begin{tabular}{cccccc}
\hline \multirow{2}{*}{ Sample } & \multicolumn{3}{c}{ Isoflavonoids (mg/g extract) } \\
\cline { 2 - 5 } & Puerarin & Daidzin & Daidzein & Genistin & Genistein \\
\hline S050 (extracted by using 50 \% ethanol) & $0.842 \pm 0.49$ & $0.314 \pm 0.34$ & $0.227 \pm 0.20$ & $0.038 \pm 0.12$ & $0.034 \pm 0.01$ \\
S075 (extracted by using 75\% ethanol) & $0.745 \pm 0.90$ & $0.290 \pm 0.39$ & $0.167 \pm 0.21$ & $0.058 \pm 0.26$ & $0.068 \pm 0.12$ \\
S095 (extracted by using 95 \% ethanol) & $5.012 \pm 0.37$ & $2.278 \pm 0.36$ & $1.886 \pm 0.65$ & $0.620 \pm 0.28$ & $0.457 \pm 0.05$ \\
V050 (extracted by using 50 \% ethanol) & $0.640 \pm 0.02$ & $0.426 \pm 0.06$ & $0.111 \pm 0.11$ & - & $0.066 \pm 0.01$ \\
V075 (extracted by using 75\% ethanol) & $1.170 \pm 0.25$ & $1.125 \pm 0.19$ & $0.302 \pm 0.36$ & $0.068 \pm 0.07$ & $0.075 \pm 0.01$ \\
V095 (extracted by using 95\% ethanol) & $1.114 \pm 0.17$ & $1.083 \pm 0.05$ & $0.325 \pm 0.35$ & $0.052 \pm 0.09$ & $0.075 \pm 0.02$ \\
\hline
\end{tabular}

$\mathrm{S}=$ Sample from Thailand, $\mathrm{V}=$ Sample from Vietnam

TABLE-3

DESCRIPTIONS FACTORS OF Pueraria candollei var. mirifica TO THE DIFFERENCES OF ACTIVE COMPOUNDS [Ref. 25]

\begin{tabular}{|c|c|c|}
\hline Sample & Descriptions & Results \\
\hline \multirow{5}{*}{$\begin{array}{l}\text { Pueraria } \\
\text { candollei } \\
\text { var. } \\
\text { mirifica }\end{array}$} & $\begin{array}{l}\text { Same sub-species, geographical proximity (e.g. province, } \\
\text { district, village or mountain) and harvesting period. }\end{array}$ & $\begin{array}{l}\text { They have the same chemical constituent but different } \\
\text { quantities. }\end{array}$ \\
\hline & $\begin{array}{l}\text { Same sub-species, geographical proximity, different harvesting } \\
\text { period. }\end{array}$ & $\begin{array}{l}\text { They have a greater difference in the quantity of active } \\
\text { compounds than the first group. }\end{array}$ \\
\hline & $\begin{array}{l}\text { Same sub-species, different geographical proximity but same } \\
\text { harvesting period. }\end{array}$ & They are small differences in chemical constituents and ratio. \\
\hline & $\begin{array}{l}\text { Same sub-species, different geographical proximity and different } \\
\text { harvesting period. }\end{array}$ & $\begin{array}{l}\text { They probably have differences in the level of actives } \\
\text { compounds. }\end{array}$ \\
\hline & $\begin{array}{l}\text { Different sub-species, different geographical proximity and } \\
\text { different harvesting period. }\end{array}$ & The level of actives compounds and ratio are different. \\
\hline
\end{tabular}


TABLE-4

QUANTITY OF MIROESTROL AND DEOXYMIROESTROL IN Pueraria candollei var. mirifica EXTRACTS

\begin{tabular}{|c|c|c|c|c|}
\hline \multirow{2}{*}{ Sample } & \multicolumn{2}{|c|}{ Miroestrol (mg/g extract) } & \multicolumn{2}{|c|}{ Deoxymiroestrol (mg/g extract) } \\
\hline & Mean $\pm \mathrm{SD}$ & $\%$ RSD & Mean \pm SD & $\%$ RSD \\
\hline S050 (extracted by using $50 \%$ ethanol) & $0.293 \pm 16.30$ & 5.57 & $0.055 \pm 4.34$ & 7.92 \\
\hline S075 (extracted by using $75 \%$ ethanol) & $0.318 \pm 20.66$ & 6.50 & $0.105 \pm 7.42$ & 7.04 \\
\hline S095 (extracted by using $95 \%$ ethanol) & $1.581 \pm 98.62$ & 6.24 & $0.397 \pm 15.01$ & 3.78 \\
\hline V050 (extracted by using $50 \%$ ethanol) & $0.026 \pm 2.480$ & 9.66 & $0.011 \pm 0.44$ & 4.10 \\
\hline V075 (extracted by using $75 \%$ ethanol) & $0.227 \pm 25.82$ & 11.39 & $0.185 \pm 19.05$ & 10.28 \\
\hline V095 (extracted by using $95 \%$ ethanol) & $1.378 \pm 49.19$ & 3.57 & $0.220 \pm 13.57$ & 6.16 \\
\hline
\end{tabular}

$\mathrm{S}=$ Sample from Thailand, $\mathrm{V}=$ Sample from Vietnam

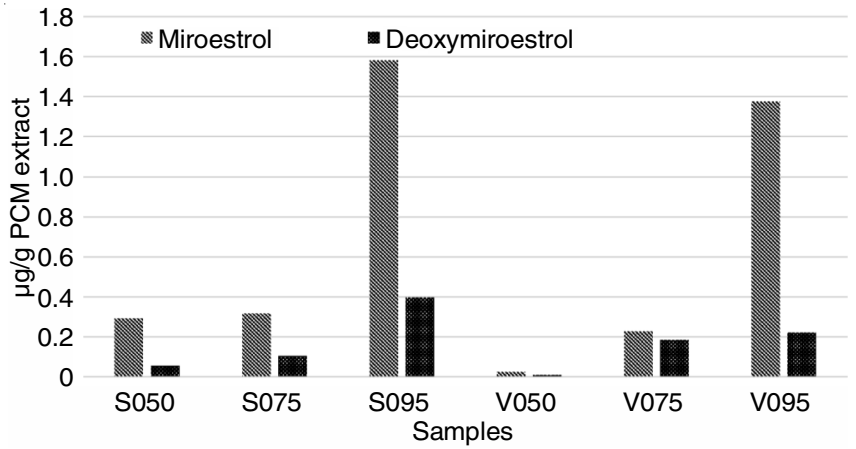

Fig. 3. Quantity of miroestrol and deoxymiroestrol from Pueraria candollei var. mirifica from Thailand and Vietnam with different ratios of solvent

Pueraria candollei var. mirifica for quantity control of crude drug as well as crude extract and it will be beneficial for suppliers and consumers before being used to develop as supplements and cosmetic products.

\section{ACKNOWLEDGEMENTS}

The authors thanks to ASEAN+3 Cross-Border Research Project Awarded by International College of Digital Innovation Chiang Mai University for grant support and also special thanks to Kovic Kate International Co., Ltd. for analytical laboratory support.

\section{CONFLICT OF INTEREST}

The authors declare that there is no conflict of interests regarding the publication of this article.

\section{REFERENCES}

1. A. Kerr J. Siam Soc. (Natural History Suppl.), 8, 336 (1932).

2. A. Sunthron Laung, The Recipe of Pueraria mirifica (tuberous root), Upatipong: Translated into English, Chiang Mai, Thailand, May (1931).

3. V. Muangman and W. Cherdshewasart, Siriraj Hosp. Gaz., 53, 300 (2001).

4. N. Urasopon, Y. Hamada, K. Asaoka, W. Cherdshewasart and S. Malaivijitnond, Maturitas, 56, 322 (2007); https://doi.org/10.1016/j.maturitas.2006.09.007.

5. N.E. Taylor, D.C. Hodgkin and J.S. Rollett, J. Chem. Soc., 33, 3685 (1960); https://doi.org/10.1039/JR9600003685.

6. S. Chansakaow, T. Ishikawa, H. Seki, K. Sekine, M. Okada and C. Chaichantipyuth, J. Nat. Prod., 63, 173 (2000); https://doi.org/10.1021/np990547v.

7. S. Chansakaow, T. Ishikawa, K. Sekine (née Yoshizawa), M. Okada, Y. Higuchi, M. Kudo and C. Chaichantipyuth, Planta Med., 66, 572 (2000); https://doi.org/10.1055/s-2000-8603.

8. M.C.L. Kashemsanta, K. Suvatabandhu and H.K.A. Shaw, Kew Bull., 7, 549 (1952);

https://doi.org/10.2307/4117811.
9. J.C. Cain, Nature, 188, 774 (1960); https://doi.org/10.1038/188774a0.

10. G.K. Benson, A.T. Cowie and Z.D. Hosking, J. Endocrinol., 21, 401 (1961); https://doi.org/10.1677/joe.0.0210401.

11. L. Udomsuk, T. Juengwatanatrakul, W. Putalun and K. Jarukamjorn, Nutr. Res., 32, 45 (2012); https://doi.org/10.1016/j.nutres.2011.11.003.

12. L. Udomsuk, T. Juengwatanatrakul, W. Putalun and K. Jarukamjorn, Phytomedicine, 19, 1332 (2012); https://doi.org/10.1016/j.phymed.2012.06.007.

13. L. Udomsuk, T. Juengwattanatrakul, K. Jarukamjorn and W. Putalun, Acta Physiol. Plant., 34, 1093 (2012); https://doi.org/10.1007/s11738-011-0906-6.

14. H.E.H. Jones, H.P. Waynforth and G.S. Pope, J. Endocrinol., 22, 293 (1961); https://doi.org/10.1677/joe.0.0220293.

15. J.L. Ingham, S. Tahara and S.Z. Dziedzic, Z. Naturforsch. B, 41c, 403 (1986).

16. https://www.scribd.com/document/68525495/Origin-Description-ofPueraria-Mirifica-Vol162.

17. D.F. Birt, S. Hendrich and W. Wang, Pharmacol. Ther., 90, 157 (2001); https://doi.org/10.1016/S0163-7258(01)00137-1.

18. T.A. Ryan-Borchers, J.S. Park, B.P. Chew, M.K. McGuire, L.R. Fournier and K.A. Beerman, Am. J. Clin. Nutr., 83, 1118 (2006); https://doi.org/10.1093/ajen/83.5.1118.

19. M. Iwasaki, M. Inoue, T. Otani, S. Sasazuki, N. Kurahashi, T. Miura, S. Yamamoto and S. Tsugane, J. Clin. Oncol., 26, 1677 (2008); https://doi.org/10.1200/JCO.2007.13.9964.

20. M.R. Haferkamp, Environmental Factors Affecting Plant Productivity, Fort Keogh Research Symposium, September, pp. $27-32$ (1987).

21. J.-G. Cho, H.-J. Park, G.-W. Huh, S.S. Lee, M.-H. Bang, K.-S. Choi, C.-H. Oh, S.-K. Ko, S.-Y. Cho, K.-Y. Chai, J.-H. Kim and N.-I. Baek, Food Sci. Biotechnol., 23, 1815 (2014); https://doi.org/10.1007/s10068-014-0248-4.

22. W. Cherdshewasart, Extracts Derived from Pueraria mirifica, Butea superba and/or Mucuna collettii and Extraction thereof, US Patent 6673377 B1 (2004)

23. M.A. Rostagno, M. Palma and C.G. Barroso, Anal. Chim. Acta, 522 , 169 (2004); https://doi.org/10.1016/j.aca.2004.05.078.

24. B. Klejdus, R. Mikelova, V. Adam, J. Zehnalek, J. Vacek, R. Kizek and V. Kubao, Anal. Chim. Acta, 517, 1 (2004); https://doi.org/10.1016/j.aca.2004.05.003.

25. ICH, Guidance for Industry, Q2B Validation of Analysis Procedures: Methodology, Step 4, Consensus Guideline, November (1996).

26. J. Zheng and K. Row, Chin. J. Chem. Eng., 15, 291 (2007); https://doi.org/10.1016/S1004-9541(07)60073-1.

27. G. Yusakul, O. Udomsin, T. Juengwatanatrakul, C. Chaichantipyuth, H. Tanaka and W. Putalun, Talanta, 114, 73 (2013); https://doi.org/10.1016/j.talanta.2013.04.011.

28. T. Kitisripanya, K. Jutathis, C. Inyai, J. Komaikul, O. Udomsin, G. Yusakul, H. Tanaka and W. Putalun, J. Nat. Med., 70, 296 (2016); https://doi.org/10.1007/s11418-015-0949-x.

29. G.S. Alexander, Confidential Review of the Efficacy, Safety and Applications of Puerariacondolleivar. mirifica Airy Shaw root: A Unique Thai Botanical Medicine with Potential as U.S. Dietary Supplement for Oral and Topical Use, American Institute for Biosocial and Medical Research, Puyallup, Washington (2001). 